\title{
The effectiveness of the new (7th) UICC $N$ classification in the prognosis evaluation of gastric cancer patients: a comparative study between the 5th/6th and 7th UICC N classification
}

\author{
Sumin Chae $\cdot$ Anbok Lee $\cdot$ Joo-Ho Lee
}

Received: 22 August 2010/Accepted: 14 December 2010/Published online: 1 March 2011

(C) The International Gastric Cancer Association and The Japanese Gastric Cancer Association 2011

\begin{abstract}
Background The most important prognostic factor after curative surgery for gastric carcinoma is the presence of lymph node metastases. According to the 7th edition of the UICC TNM staging system for gastric cancer, $\mathrm{N}$ classification was categorized as N0 (no regional lymph node metastasis), N1 (1-2 regional lymph node metastases), N2 (3-6 regional lymph node metastases), and N3 (7 or more regional lymph node metastases). The purpose of this study was to evaluate the rationality of the new UICC/AJCC N classification in comparison with the 6th UICC classification.

Methods From August 2002 to July 2006, 295 patients with gastric cancer underwent curative resection with D2 lymph node dissection by a single surgeon. We analyzed retrospectively the significant prognostic factors and identified the suitability of the 7th UICC N staging system.

Results According to the 7th UICC N classification, the 5 -year cumulative survival rates (5-YSR) of N0, N1, N2, $\mathrm{N} 3 \mathrm{a}$, and N3b were 89.7, 73.6, 54.9, 23.1, and 5.4\%, respectively $(P<0.0001)$. Using univariate analysis, the $\mathrm{N}$ classification of the 7th and 6th UICC/AJCC TNM staging system, T classification of the 7th UICC TNM staging system, size and location of tumor, and histology were associated with the overall survival of gastric cancer after curative surgery. However, Cox regression multivariate analysis showed the 7th UICC $\mathrm{N}$ classification was an independent prognostic factor instead of the 6th UICC N classification $(P<0.0001)$.
\end{abstract}

S. Chae $\cdot$ A. Lee $\cdot$ J.-H. Lee $(\square)$

Department of Surgery, Mok-dong Hospital,

Ewha Womans University, School of Medicine,

911-1 Mok-dong, Yangcheon-ku, Seoul 158-710, Korea

e-mail: gsljh@ewha.ac.kr
Conclusion The 7th UICC classification for lymph node metastasis is thought to be a more reliable prognostic factor for gastric cancer than the 6th classification.

Keywords 7th UICC N classification - Prognostic factor · Gastric cancer

\section{Introduction}

Gastric cancer is one of the most common causes for cancer-related deaths [1]. Like other cancers, the TNM system has been used for the determination of gastric cancer stage. The objectives of the staging system are to aid the clinician in the planning of treatment, give some indication of prognosis, assist in the evaluation of the results of treatment, and facilitate the exchange of information [2]. The TNM system is accepted as a golden standard for the staging system of malignancy all over the world. The depth of primary tumor infiltration and number of metastatic lymph nodes (LNs) are known to be the most important prognostic factors of gastric cancer after curative surgery [3-7]. Especially the extent of LN metastasis is considered to be the most important independent prognostic factor $[8,9]$. There are two major classification systems used for gastric cancer staging: the Japanese Classification of Gastric Cancer (JCGC) and the Union Internationale Contra le Cancer (UICC)/TNM classification system. The JCGC node staging system is based on the location of the metastatic lymph node [10]. The 4th UICC $\mathrm{N}$ stage was also based on the extent of anatomical lymphatic spread (less than or greater than $3 \mathrm{~cm}$ from the primary tumor) [11]. However, since the 5th edition UICC TNM classification, the $\mathrm{N}$ stage has been based on the number of metastatic lymph nodes [12]. 
The introduction of the 7th edition UICC TNM classification for gastric cancer has brought several changes from the 5 th/6th edition as well as for other cancers. There had been some debates about the efficacy of the 6th UICC N staging, and the most prominent alteration of the 7th edition UICC TNM classification was in $\mathrm{N}$ staging. The 7th UICC N stage was redefined as follows: N0 (no regional lymph node metastasis), N1 (metastases in 1-2 regional lymph nodes), N2 (metastases in 3-6 regional lymph nodes), N3a (metastases in 7-15 regional lymph nodes), and $\mathrm{N} 3 \mathrm{~b}$ (metastases in more than 15 regional lymph nodes) [13]. In determining the prognostic factor of surgical patients, the unified surgical technique and postoperative care should be considered as one of the most important requirements. The patients enrolled in this study underwent curative surgery by a single well-experienced surgeon, which would minimize the bias from surgeon's factor.

The aim of this study was to identify the suitability of the 7th UICC N staging system in comparison with the 6th UICC classification with minimal bias from the surgeon factor.

\section{Patients and methods}

Patients

From August 2002 to July 2006, 295 patients with gastric cancer underwent curative resection (subtotal, total or combined resection) by a single surgeon at the Department of Surgery, Ewha Womans University Mok-dong Hospital, Seoul, Korea.

We excluded the following patients from this study: (1) patients with distant metastasis, (2) patients with noncurative resection (R1 or R2 resection), (3) patients with D1 lymph node (LN) dissection, and (4) patients with less than 15 dissected LNs.

The study group included 174 men and 121 women, constituting a male-to-female ratio of 1:0.7. The mean age of patients was 60.0 years (range 24-86). The mean tumor size was $4.3 \mathrm{~cm}$ (range $0.4-18.0$ ). The mean number of dissected LNs was 47.7 (range 15-116). LN metastasis was detected in 145 patients $(49.2 \%)$, and the mean number of metastatic LNs was 5.4 (range 0-66). With respect to tumor location, the tumor was located in the upper third of the stomach in 43 patients (14.6\%), at the mid third in 112 patients $(38.0 \%)$, and at the lower third in 140 patients $(47.4 \%)$. In terms of operation method, 181 patients $(61.4 \%)$ underwent subtotal gastrectomy, 83 patients $(28.1 \%)$ underwent total gastrectomy, and the remaining 31 patients $(10.5 \%)$ underwent combined resection (Table 1).
Table 1 Univariate analysis of clinicopathologic factors for 5-year survival rate

\begin{tabular}{|c|c|c|c|}
\hline Factor & Number & $\begin{array}{l}5 \text {-year survival } \\
\text { rate }(\%)\end{array}$ & $P$ value \\
\hline Gender & & & 0.0918 \\
\hline Male & 174 & 62.8 & \\
\hline Female & 121 & 70.8 & \\
\hline Age at surgery & & & 0.1822 \\
\hline$<40$ & 16 & 81.2 & \\
\hline $40-64$ & 151 & 68.8 & \\
\hline$\geq 65$ & 128 & 61.0 & \\
\hline Size of tumor & & & $<0.0001$ \\
\hline$<2$ & 67 & 92.5 & \\
\hline $2-5$ & 132 & 70.3 & \\
\hline $5-10$ & 76 & 45.6 & \\
\hline$\geq 10$ & 20 & 29.1 & \\
\hline Location of tumor & & & $<0.0001$ \\
\hline Upper & 43 & 66.4 & \\
\hline Mid & 112 & 64.2 & \\
\hline Lower & 140 & 68.1 & \\
\hline T stage (7th UICC) & & & $<0.0001$ \\
\hline T1a & 61 & 95.0 & \\
\hline $\mathrm{T} 1 \mathrm{~b}$ & 58 & 94.8 & \\
\hline $\mathrm{T} 2$ & 31 & 83.1 & \\
\hline $\mathrm{T} 3$ & 10 & 70.0 & \\
\hline $\mathrm{T} 4 \mathrm{a}$ & 120 & 38.3 & \\
\hline $\mathrm{T} 4 \mathrm{~b}$ & 15 & 26.6 & \\
\hline $\mathrm{N}$ stage (6th UICC) & & & $<0.0001$ \\
\hline No & 150 & 89.7 & \\
\hline N1 & 76 & 66.2 & \\
\hline $\mathrm{N} 2$ & 32 & 23.1 & \\
\hline N3 & 37 & 5.4 & \\
\hline $\mathrm{N}$ stage (7th UICC) & & & $<0.0001$ \\
\hline No & 150 & 89.7 & \\
\hline N1 & 46 & 73.6 & \\
\hline $\mathrm{N} 2$ & 30 & 54.9 & \\
\hline N3a & 32 & 23.1 & \\
\hline $\mathrm{N} 3 \mathrm{~b}$ & 37 & 5.4 & \\
\hline Histology & & & 0.0003 \\
\hline Well differentiated & 44 & 87.8 & \\
\hline Moderately differentiated & 81 & 71.2 & \\
\hline Poorly differentiated & 170 & 57.8 & \\
\hline
\end{tabular}

Age $(<40,40 \leq$ age $<64, \geq 65)$, sex (male or female), tumor size $(<2,2 \leq \mathrm{T}<5,5 \leq \mathrm{T}<10, \geq 10)$, tumor location (upper, mid, lower), $\mathrm{T}$ stage (7th UICC), $\mathrm{N}$ stage (6th UICC), $\mathrm{N}$ stage (7th UICC), and tumor histology (well, moderate, and poorly differentiated) were retrospectively analyzed to find significant prognostic factors. All patients were followed up, and the median follow-up duration was 57.2 months (range 1.3-93.7). Patient data 
were obtained from our own and Korea Central Cancer Registry database.

Statistical analysis

All data were analyzed by statistical analysis program package (SPSS 17.0, SPSS Inc., Chicago, IL). Overall survival (OS) was calculated using the Kaplan-Meier method, and the log-rank test was employed to determine the significance. Multivariate analysis was performed by the Cox proportional hazard model. $P<0.05$ was considered as a statistically significant result.

\section{Results}

Pairwise comparison of 5-year survival rate (5-YSR) according to UICC $\mathrm{N}$ stage

The overall 5-YSR of 295 patients was $66.1 \%$. The comparative study of patients' 5-YSRs according to the 5th/6th UICC N stage showed the following: N0 versus N1 $(89.7$ vs. $66.2 \%, p<0.0001), \mathrm{N} 1$ versus $\mathrm{N} 2$ (66.2 vs. 23.1 , $p<0.0001$ ), and $\mathrm{N} 2$ versus $\mathrm{N} 3$ (23.1 vs. $5.4 \%, P=$ 0.0018) (Fig. 1). In comparison, 5-YSRs according to the 7th UICC N stage were as follows: N0 versus N1 (89.7 vs. $73.6 \%, P=0.0040), \mathrm{N} 1$ versus $\mathrm{N} 2(73.6$ vs. $54.9 \%$, $P=0.0155)$, N2 versus N3a (54.9 vs. $23.1 \%, P=0.0123$ ), and N3a versus N3b (23.1 vs. $5.4 \%, P=0.0018$ ) (Fig. 2; Table 2).

Univariate and multivariate analysis for prognostic factors

In univariate analysis, tumor size, tumor location, $\mathrm{T}$ stage (7th UICC), N stage (6th UICC), N stage (7th UICC), and histologic type were significantly correlated with patients' OS (Table 1).

We performed multivariate Cox proportional hazard model analysis for age, sex, and six factors that had significant correlation with OS. The result showed that the 7th UICC $\mathrm{N}$ stage, 7th UICC $\mathrm{T}$ stage, and age were the independent prognostic factors for gastric cancer after curative gastrectomy with D2 dissection (Table 3).

\section{Discussion}

The overall incidence of gastric cancer has decreased over the last few years. Some Japanese studies suggested that it could be due to changes in dietary habits, keeping foods refrigerated, and a decrease in the incidence of $H$. pylori infection [14]. The mortality rate of gastric cancer has also

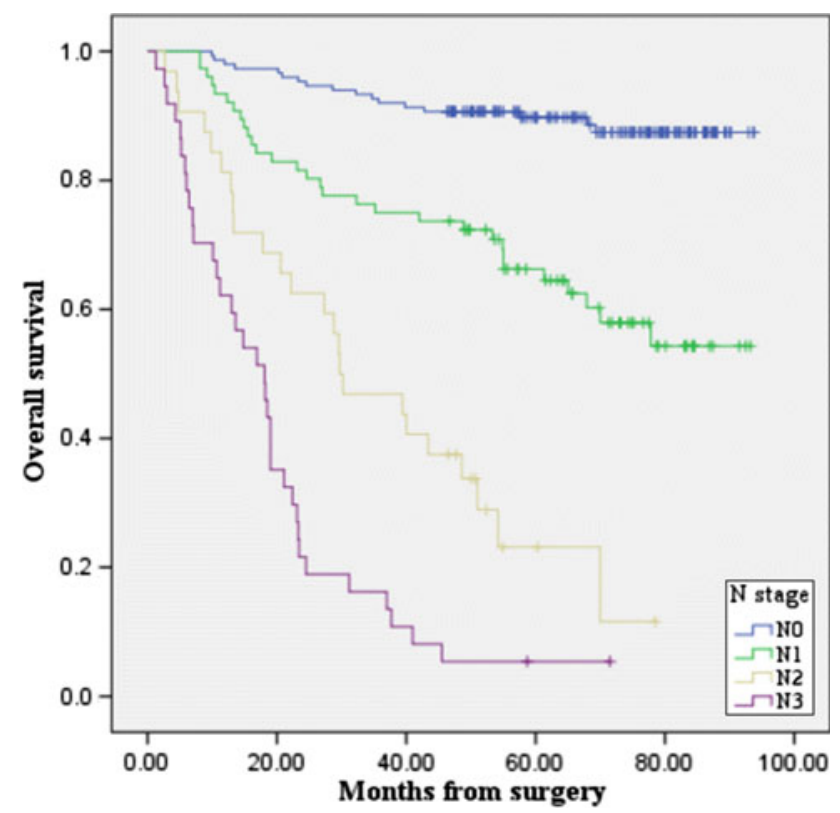

Fig. 1 Survival curves for 295 patients according to the 5th/6th UICC N stage

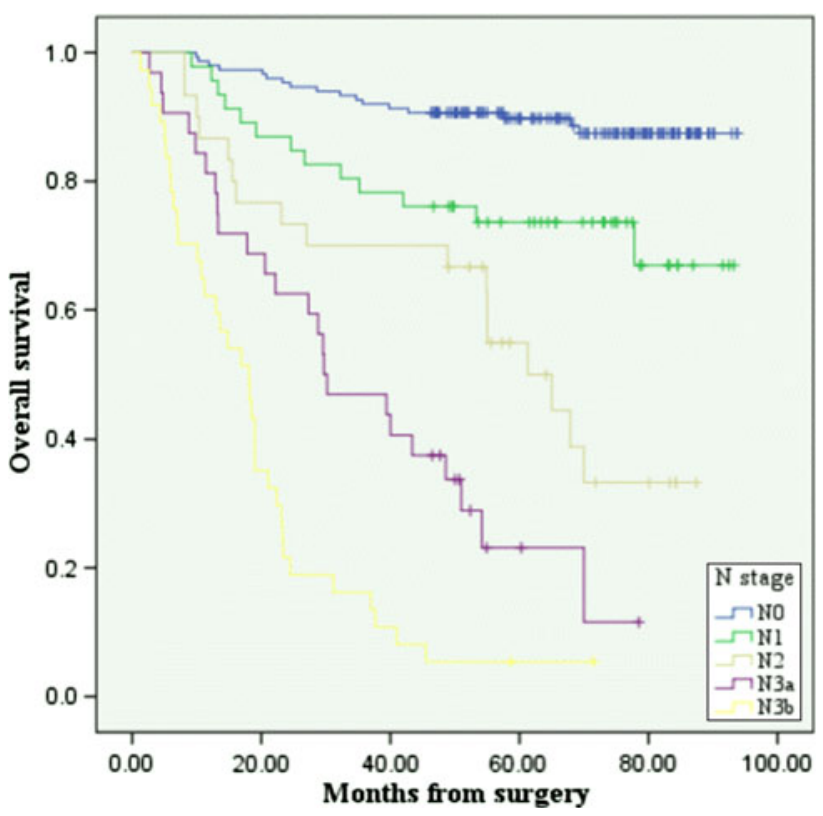

Fig. 2 Survival curves for 295 patients according to the 7 th UICC N stage

declined because of early diagnosis, early treatment, and the advancement of operation technique [4]. However, the prognosis of gastric cancer is still dismal. Therefore, the prediction of prognostic factors plays a very important role in the treatment of patients with gastric cancer. Among the well-known prognostic factors for gastric cancer [3, 4, 8, 15-18], depth of tumor invasion, and LN metastasis are the most important independent prognostic factors $[3-5,7]$. 
Table 2 Comparison of 5-year survival rates between the 5th/6th and 7th UICC N stage

\begin{tabular}{|c|c|c|c|c|c|}
\hline \multicolumn{3}{|c|}{ 5th/6th UICC N stage } & \multicolumn{3}{|l|}{ 7th UICC N stage } \\
\hline Subgroup & 5-year survival rate & $P$ value & Subgroup & 5-year survival rate & $P$ value \\
\hline N0 versus N1 & 89.7 versus $66.2 \%$ & $<0.0001$ & N0 versus N1 & 89.7 versus $73.6 \%$ & 0.0040 \\
\hline $\mathrm{N} 1$ versus $\mathrm{N} 2$ & 66.2 versus $23.1 \%$ & $<0.0001$ & $\mathrm{~N} 1$ versus $\mathrm{N} 2$ & 73.6 versus $54.9 \%$ & 0.0155 \\
\hline \multirow[t]{2}{*}{$\mathrm{N} 2$ versus $\mathrm{N} 3$} & 23.1 versus $5.4 \%$ & 0.0018 & $\mathrm{~N} 2$ versus N3a & 54.9 versus $23.1 \%$ & 0.0123 \\
\hline & & & $\mathrm{N} 3 a$ versus $\mathrm{N} 3 \mathrm{~b}$ & 23.1 versus $5.4 \%$ & 0.0018 \\
\hline
\end{tabular}

Table 3 Multivariate analysis with Cox proportional hazard model for prognostic factors

\begin{tabular}{lcll}
\hline Factor & $P$ value & HR & $95 \%$ CI \\
\hline Age & 0.002 & 1.775 & $1.240-2.541$ \\
7th N stage (UICC) & $<0.0001$ & 1.975 & $1.669-2.338$ \\
6th N stage (UICC) & 0.744 & 1.155 & $0.487-2.742$ \\
7th T stage (UICC) & $<0.0001$ & 1.033 & $1.015-1.052$ \\
\hline
\end{tabular}

Status of LN metastasis is categorized by two systems. The first one originated in Japan in the 1980s. This system defines $\mathrm{N}$ stage by location of $\mathrm{LN}$ metastasis relative to the primary tumor according to the Japanese Classification of Gastric Carcinoma (JCGC) [10]. The other one, based on the number of metastatic LNs, was suggested by Union Internationale Contra le Cancer (UICC), 5th edition, in 1997 [12-19]. TNM classification for malignancy was developed by Pierre Denoix between 1943 and 1952 [2]. In case of gastric cancer, it was first included in the TNM classification in 1966. Before the fifth edition, $\mathrm{N}$ classification for gastric cancer was based on the anatomic location of metastatic LNs $[4,11]$. However, in the 5th UICC classification, $\mathrm{N}$ status was categorized according to the number of metastatic LNs [20]. Many studies reported that UICC N stage, which is based on the number of metastatic LNs, was superior to the JCGC in terms of feasibility, objectivity, and reproducibility and for the accuracy of prognostic prediction $[21,22]$. The defined 5th UICC N classification was as follows: N0 (no regional LN metastasis), N1 (metastases in 1-6 LNs), N2 (metastases in 7-15 LNs), and N3 (metastases in $\geq 16$ LNs) [12]. In the 6th edition of the UICC classification, there was no change in $\mathrm{N}$ classification. The TNM classification requires at least 15 harvested LNs for accurate staging. Because of this, there were some studies on the ratio of metastatic lymph nodes (based on the number of positive LNs divided by the number of examined LNs) for preventing the stage migration phenomenon [23, 24]. Kim et al. [18] also showed that the $\mathrm{N}$ ratio was an independent prognostic factor and reported that it had more comprehensive and precise prognostic value than the number of involved or resected LNs when radical LN dissection was performed.
However, more studies will be necessary in this area as well [25].

Recently, the introduction of the 7th edition UICC TNM classification for gastric cancer has made several changes from the 5th/6th edition. According to the new classification, $\mathrm{T}$ stage was classified to T1a (lamina propria invasion), T1b (submucosa invasion), T2 (muscularis propria invasion), T3 (subserosa invasion), T4a (serosa invasion), and T4b (adjacent organ invasion). The 7th UICC $\mathrm{N}$ stage was redefined as follows: NO (no regional lymph node metastasis), N1 (metastases in 1-2 LNs), N2 (metastases in 3-6 LNs), N3a (metastases in 7-15 LNs), and N3b (metastases in $\geq 16 \mathrm{LNs}$ ) [13].

Actually, the suitability of the 5th/6th UICC N classification and its necessity of $\mathrm{N}$ classification modification had been suggested by some investigators prior to the introduction of the 7th edition UICC TNM classification $[25,26]$. The authors from Japan reported that the relative risk for $\mathrm{pN} 3$ was not significantly higher than for $\mathrm{pN} 2$ in their study, and there was difficulty defining cutoff points in a number-based classification [27]. In the study of $\mathrm{Hu}-$ ang et al. [26], they demonstrated that the 6th UICC N classification was not suitable for early gastric cancer and suggested N0 (no regional LN metastasis), N1 (metastases in 1-3 LNs), $\mathrm{N} 2$ (metastases in 4-6 LNs), and N3 (metastases in $\geq 7 \mathrm{LNs}$ ) as a new $\mathrm{N}$ classification. Deng et al. [25] also reported the necessity of $\mathrm{N}$ classification modification and redesigned cutoffs of the number of metastatic lymph nodes.

In order to determine which one is a more effective classification method between the 7th UICC N and the 5th/ 6th UICC N, we analyzed 295 patients who underwent curative gastrectomy by a single, well-experienced surgeon to determine the superiority of the 7th UICC $\mathrm{N}$ classification and other prognostic factors. In univariate analysis, significant prognostic factors were the tumor size, tumor location, the 7th UICC T stage, the 6th UICC N stage, and the 7th UICC N stage. However, the multivariate analysis result showed that the 7th UICC $\mathrm{T}$ and $\mathrm{N}$ stage were significantly independent prognostic factors (Table 3). Survivals according to the 7th UICC $\mathrm{N}$ stage were more evenly distributed than survivals according to the 5th/6th UICC N stage (Figs. 1, 2). Yang et al. [28] also reported that the 7th 
UICC $\mathrm{T}$ and $\mathrm{N}$ stages were more evenly distributed than the 6th UICC $\mathrm{T}$ and $\mathrm{N}$ stages. Deng et al. [9] reported the superiority of the 7th UICC N stage, based on the evidence of the significant difference of 5-year survival rate between $\mathrm{N} 1$ and $\mathrm{N} 2$ substages of the 7th UICC $\mathrm{N}$ stage and no significant prognostic difference between N2 and N3 substages of the 5 th/6th UICC N stage. They argued N2 and N3 substages of the 5th/6th UICC N classification should be integrated into only one substage as N3 instead of N3a and $\mathrm{N} 3 \mathrm{~b}$ in the 7 th UICC $\mathrm{N}$ classification. However, in our study, there was a significant difference in the 5-year survival rate between the 7 th UICC N3a and N3b. And several data indicated there was a significant difference in survivals between $\mathrm{N} 2$ and $\mathrm{N} 3$ in the 6 th $\mathrm{N}$ classification [4, 21, 29]. But in the 7th UICC edition, this difference was not reflected in the gastric cancer stage, and it seems that there should be a compensation for this problem.

\section{Conclusion}

Our study revealed that the 7th UICC $\mathrm{T}$ and $\mathrm{N}$ classification were significantly independent prognostic factors, and the 7th UICC $\mathrm{N}$ classification seems to provide a more reliable prognostic result than the 6th UICC N classification. However, we think that there should be a compensation for the 7th UICC gastric cancer stage because of the difference in survival rate between the 7th UICC N3a and N3b.

Acknowledgment This study was supported by grants 2010 from Ewha Womans University Mokdong Hospital.

\section{References}

1. Takeuchi H, Kitagawa Y. Is lymphadenectomy a predictor or savior for patients with gastric cancer? Ann Surg Oncol. 2010;17:1257-8

2. Sobin LH. TNM: principles, history, and relation to other prognostic factors. Cancer. 2001;91:1589-92.

3. Manfe AZ, Segalina P, Maffei Faccioli A. Prognostic factors in gastric cancer. Our experience and review of the literature. Minerva Chir. 2000;55:299-305.

4. Del Rio P, Dell'Abate P, Soliani P, Arcuri MF, Tacci S, Ziegler $S$, et al. Old and New TNM in carcinoma of gastric antrum: analysis of our personal experience. J Gastrointest Surg. 2003;7:912-6.

5. Maruyama K, Sasako M, Kinoshita T. Prognostic factors of gastric cancer patients and new TNM classification [abstract]. Gut. 1999;45(suppl 5):66A.

6. D'Ugo D, Pacelli F, Persiani R, Pende V, Ianni A, Papa V, et al. Impact of the latest TNM classification for gastric cancer: retrospective analysis on 94 D2 gastrectomies. World J Surg. 2002;26:672-7.

7. Kim JP, Kim YW, Yang HK, Noh DY. Significant prognostic factors by multivariate analysis of 3926 gastric cancer patients. World J Surg. 1994;18:872-7.
8. Siewert JR, Bottecher K, Stein HJ, Roder JD. Relevant prognostic factors in gastric cancer. Ten-year results of the German Gastric Cancer Study. Ann Surg. 1998;228:449-61.

9. Deng JY, Liang H, Sun D, Wang D, Pan Y. Suitability of 7th UICC N stage for predicting the overall survival of gastric cancer patients after curative resection in China. Ann Surg Oncol. 2010;17:1259-66.

10. Japanese Gastric Cancer Association. Japanese classification of gastric carcinoma-2nd English edition. Gastric Cancer 1998; 1: $10-24$

11. Hermanek P, Sobin L.H (eds) TNM Classification of Malignant Tumors (UICC). 4th edn. Berlin: Springer; 1987. pp. 43-46

12. Sobin LH, Wittekind $\mathrm{CH}$. TNM classification of malignant tumors (UICC). 5th ed. New York: Wiley; 1997. p. 59-62.

13. Sobin LH, Wittekind C, Gospodarowicz M (eds) TNM classification of malignant tumors (UICC). 7th edn. New York: WileyBlackwell; 2009. pp. 73-77

14. Kaneko S, Yoshimura T. Time trend analysis of gastric cancer incidence in Japan by histological types, 1975.1989. Br J Cancer. 2001;84:400-5.

15. Yamamura $Y$, Nakajima $T$, Ohta $K$, Nashimoto A, Arai $K$, Hiratsuka $\mathrm{M}$, et al. Determining prognostic factors for gastric cancer using the regression tree method. Gastric Cancer. 2002;5:201-7.

16. Kooby DA, Suriawinata A, Klimstra DS, Brennan MF, Karpeh MS. Biologic predictors of survival in node-negative gastric cancer. Ann Surg. 2003;237:828-35.

17. Yokota T, Kunii Y, Teshima S, Yamada Y, Saito T, Takahashi M, et al. Significant prognostic factors in patients with early gastric cancer. Int Surg. 2000;85:286-90.

18. Kim JP, Lee JH, Kim SJ, Yu HJ, Yang HK. Clinicopathologic characteristics and prognostic factors in 10783 patients with gastric cancer. Gastric Cancer. 1998;1:125-33.

19. Omejc M, Juvan R, Jelenc F, Repse S. Lymph node metastases in gastric cancer: Correlation between new and old UICC TNM classification. Int Surg. 2001;86:14-9.

20. Hermanek P. The superiority of the new international Union Against Cancer and American Joint Committee on Cancer TNM staging of gastric carcinoma. Cancer. 2000;88:1763-5.

21. Ichikura T, Tomimatsu S, Uefuji K, Kimura M, Uchida T, Morita $\mathrm{D}$, et al. Evaluation of the new American Joint Committee on Cancer/International Union against cancer classification of lymph node metastasis from gastric carcinoma in comparison with the Japanese classification. Cancer. 1999;86:553-8.

22. Celen O, Yildirim E, Gulben K, Berberoglu U. Prediction of survival in gastric carcinoma related to lymph node grading by the new American Joint Committee on Cancer/Union International Contre le Cancer System or the Japanese system. Eur J Surg Suppl. 2003;588:33-9.

23. Inoue $\mathrm{K}$, Nakane $\mathrm{Y}$, Iiyama H, Sato M, Kanbara T, Nakai K, et al. The superiority of ratio-based lymph node staging in gastric carcinoma. Ann Surg Oncol. 2002;9:27-34.

24. Persiani R, Rausei S, Biondi A, Boccia S, Cananzi F, D’Ugo D. Ratio of metastatic lymph nodes: impact on staging and survival of gastric cancer. Eur J Surg Oncol. 2007;34:519-24.

25. Deng JY, Liang H, Sun D, Zhan HJ, Wang XN. The most appropriate category of metastatic lymph nodes to evaluate overall survival of gastric cancer following curative resection. J Surg Oncol. 2008;98:343-8.

26. Huang B, Zheng X, Wang Z, Wang M, Dong Y, Zhao B, et al. Prognostic significance of the number of metastatic lymph nodes: is UICC/TNM node classification perfectly suitable for early gastric cancer? Ann Surg Oncol. 2009;16:61-7.

27. Katai H, Yoshimura K, Maruyama K, Sasako M, Sano T. Evaluation of the new International Union Against Cancer TNM staging for gastric carcinoma. Cancer. 2000;88:1796-800. 
28. Yang H, Ahn H, Yoon H, Kong S, Cho J, Park D, et al. Application of new TNM staging system for gastric cancer and prognostic significance of the number of metastatic lymph nodes. abstract 8th IGCC 2009, S51, pp. 29
29. Klein Kranenbarg E, Hermans J, van Krieken JH, van de Velde CJ. Evaluation of the 5th edition of the TNM classification for gastric cancer: improved prognostic value. $\mathrm{Br} \mathrm{J}$ Cancer. 2001;84(1):64-71. 